\title{
Data Reference in Depth: Sources of International Labour Data
}

\begin{abstract}
Most countries provide access to national labour data on the Internet, but finding it can be a frustrating exercise, especially if the country in question does not provide the information in a language understood by the researcher. Foreign labour data are also often sought when attempting to make international comparisons of particular labour statistics. This article reviews Internet-accessible multi-country compilations of labour data that provide access in multiple languages, with attention given to those that permit international comparisons to be made.
\end{abstract}

Keywords: labour data, labor data, comparative data, international data

While data and statistics on labour and employment for wide variety of countries are now readily available on the internet, finding statistics for a particular country and/ or on a particular parameter for multiple countries can be a challenge. Even more frustrating can be trying to find statistics that are comparable across countries. In this article, I will describe a number of sites that provide easy access to both national labour statistics and international and comparative labour statistics.

\section{International Labour Organization (ILO) <http://www.ilo.org>}

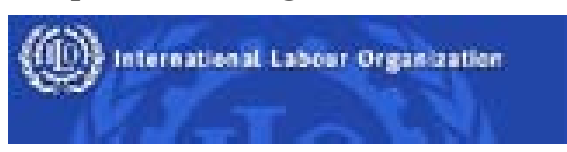

The ILO should be the first stop for labour data beyond one's own borders. It is the

hub for labour statistics within the UN system. The ILO is

"... devoted to advancing opportunities for women and men to obtain decent and productive work in conditions of freedom, equity, security and human dignity. Its main aims are to promote rights at work, encourage decent employment opportunities, enhance social protection and strengthen dialogue in handling work-related issues." 2

The ILO provides, in English, French and Spanish, official core labour statistics and estimates for over
200 countries since 1969 . Besides the data, it also provides considerable metadata, definitions and methodological descriptions of main national statistical sources. The data provided use mostly national definitions, except in limited cases; the difficulties this poses will be discussed at the end of this paper.

On the ILO home page, a link to 'Statistics and databases' is given on the right side. This page shows a list of databases, both of statistics and literature, with brief descriptions. The ones that are primarily data-related are listed under the 'Statistics' subheading:

1. LABORSTA - database of labour statistics

2. Key Indicators of the Labour Market (KILM)

3. Statistical Information and Monitoring Programme on Child Labour (IPEC-SIMPOC)

4. Labour Force Surveys

Plus, separate from these four sites, but devoted primarily to data that are more current, is

5. ILO Global Job Crisis Observatory

\section{LABORSTA}

$<$ http://laborsta.ilo.org/>

LABORSTA covers official core labour statistics and estimates for over 200 countries since 1969. Also provides methodological descriptions of main national statistical sources. [3] ${ }^{3}$ At the time of writing, there were 224 entries for countries, of which some are subnational areas included for historical reasons (e.g., the four entries for Germany: Germany as it is now, the former FRG and GDR, and the 5 new Länder plus what was East Berlin), or overseas territories (e.g., St. Pierre \& Miquelon, an overseas territory of France). The first page offers the user a choice of statistics for 11 general topics, in most cases available in both annual and monthly frequencies:

- Total and Economically Active Population

- Employment

- Unemployment 
- Hours of Work

- Wages

- Labour Cost

- Consumer Price Indices

- Occupational Injuries

- $\quad$ Strikes and Lockouts

- Household Income and Expenditure

- International Labour Migration

Following the link to 'employment', for example, leads to six links to data sources, some of which go to other databases. The hover text for each link lets the user know how far back the data go, at least as an upper limit. There is also a 'by topic' link on the left-hand menu bar that leads to a page that lists all the available topics. The user can also see what is available by country, or by publication (for those familiar with the range of topics covered by ILO Yearbook of Labour Statistics, ILO Bulletin of Labour Statistics, and ILO October Inquiry). Ultimately, the data can either be viewed online, or downloaded to Excel. The online version has links to relevant metadata embedded in it; the Excel spreadsheet has limited metadata. The user needs to look at the 'view data' page to have a clear idea of what the data represent; if nothing else, the spreadsheet should contain links to the necessary metadata.

On the LABORSTA home page (and on the left menu on all subsequent pages) is a set of metadata links:

- Definitions - of terminology used (e.g., economically active population, employment, etc.) In each case, an essay is provided with the definitions used, potential sources of data on the given concept, plus alerts as to potential problems with interpretation;

- Classifications - detailed information on the various international standard classification schemes used:

o International Classification by Status in Employment

o International Standard Classification of Education

o International Standard Classification of Occupations

o International Standard Industrial Classification of all Economic Activities

o $\quad$ System of National Accounts 1993
- Sources and methods - information on the scope of the statistics, their definitions and the methods used by the national statistical services in establishing the data published. ${ }^{4}$ This is the full text of the ten-volume series Sources and Methods: Labour Statistics ${ }^{5}$

Perusal of these metadata links is critical to a full understanding of the data and their limitations for making comparisons.

The LABORSTA homepage also contains links to short term indicators of the labour market; these are drawn from official national statistical sources, based on national definitions, and are not seasonally adjusted. They contain monthly data for the past twelve months, quarterly data for the past five quarters, and annual data for the past three years. The data are available by topic or by country; in addition, complete country profiles and selected series by country are available in PDF or XLS formats.

\section{Key Indicators of the Labour Market (KILM) $<$ http://www.ilo.org/empelm/what/lang--en/ WCMS 114240>}

Available in print, online and as a standalone software package, the KILM has been published every two years since 1999. Currently in its sixth edition, the KILM

- is a comprehensive database of country-level data on 20 key indicators of the labour market from 1980 to the latest available year;

- $\quad$ is a source of the latest ILO world and regional estimates of employment and unemployment indictors. a training tool on development and use of labour market indicators;

- $\quad$ highlights of current labour market trends;

- $\quad$ provides analyses of key issues in the labour market $^{6}$

The online version, known as KILMnet (still in beta) offers 32 tables in six groupings:

- Participation in the world of work (3 tables)

- Employment indicators (11 tables)

- Unemployment indicators (6 tables)

- Educational attainment (2 tables)

- Wages and labour costs (7 tables)

- $\quad$ Performance and poverty indicators (3 tables)

The interface is similar in some ways to that of the World 


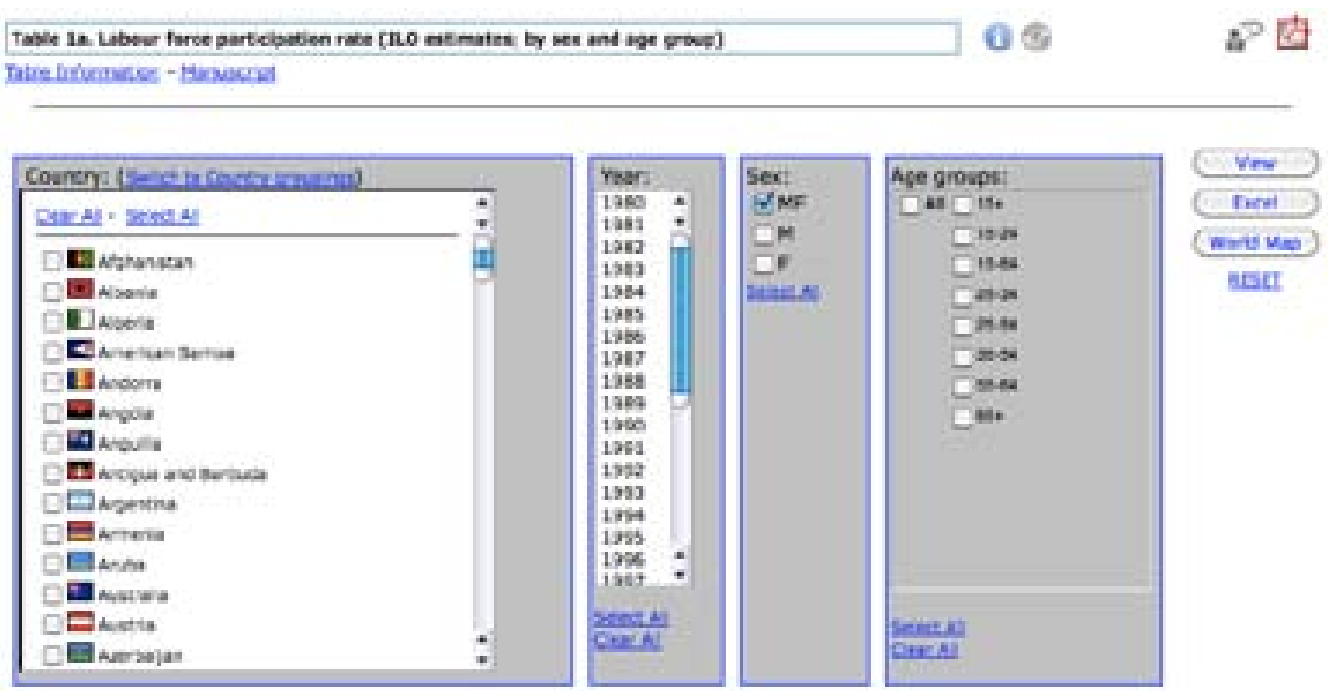

Development Indicators ${ }^{7}$, except that all the data parameter selections can be made on the same screen

The differences between the KILM and LABORSTA are addressed in the document "Guide to understanding the KILM" 8 . Basically, LABORSTA (and its print equivalent, the Yearbook of Labour Statistics) are the best source of nationally-reported labour statistics, whereas KILM supplements these data from other sources when those other sources are considered more accurate or more complete, and offer better international comparability. The KILM is not restricted to using national data as reported; it makes efforts to use indicator series that are more comparable across time and geographies. The KILM offers three comparable or harmonized series: labour force participation rates, employment-to-population ratios, and the inactivity rate. Other series have been made as comparable as possible; anomalies in definition and methodologies are clearly indicated in the table notes.

In other words, when national data are desired, the user should start with LABORSTA; when comparisons between countries are to be made, KILM should be the starting point

\section{Statistical Information and Monitoring Programme on Child Labour (IPEC-SIMPOC) $<$ http://www.ilo.org/ipec/ChildlabourstatisticsSIMPOC/ lang--en/index.htm>}

This is the statistical arm of the International Programme for the Elimination of Child Labour (IPEC). It claims to offer:

- Specific questionnaires for child labour surveys

- Manuals and training kits on how to carry out child labour data collection in households, schools and at the workplace
- Guidance on how to properly process and analyse the collected information

- Micro datasets and survey reports from around the world

- Research on critical statistical issues

- Regular trend reports

Microdata sets for 30 countries (as of 2010.09.26) are available under the left menu option "Surveys"; the data are often available for multiple years, and are provided in ASCII, SPSS or Stata,

along with metadata

\section{Labour Force Surveys} <http://www.ilo.org/dyn/lfsurvey/lfsurvey.home> This page lists links to the websites for the labour force surveys (defined as "a standard household-based survey of work-related statistics") of all the countries in the ILO. It does not provide access to the microdata, and is inconsistent as to what it does link. Using examples from countries the author of this paper is currently familiar with,

- in the case of Canada, it links to the press release associated with the most current release of the Labour Force Survey; it does not mention the Survey of Labour and Income Dynamics;

- for the United States, it links to the "Current Labor Statistics" page from the Monthly Labor Review; it provides access to labour data from both the Current Population Survey and Current Employment Statistics;

- for Australia, it simply provides a link to the "Statistics by Topic: Labour" page on the Australian Bureau of Statistics website, with no direct access to the Household, Income and Labour Dynamics in Australia (HILDA) survey

In each case, however, the ILO does provide access to a page describing the methodology of the main labour force survey of each country. Also, the user gets a link to the country's relevant website - -this in itself can be valuable, as it enables one to follow up with the country itself on any questions, as well as potentially providing access to reports on data unavailable from the ILO.

Global Statistics on the Labour Market

$<$ http://www.ilo.org/pls/apex/f?p=109:11:0>

Part of the ILO's ILO Global Job Crisis Observatory 
website ${ }^{9}$, this site offers "the latest national data for indicators which have been selected for their ability to reflect recent and short term changes." Data are available by topic or country, and are not seasonally adjusted or otherwise altered by the ILO. Updates of indicators and associated publications are usually monthly, but can be more or less frequent.

\section{OTHER DATA SITES}

The ILO is not the only site from which one can get compiled labour data from a variety of countries. The following section of this paper describes some others.

\section{International Labor Comparisons (US)}

<http://www.bls.gov/data/\#international>

This site provides labour data for selected countries using a variety of indicators, all of which are adjusted to U.S. concepts ${ }^{10}$ unless otherwise noted. Data series are presented as: a group of most requested series; either a one-screen or multi-screen data search process; a series of static tables (in HTML, PDF or XLS formats). Some series, such as the supplementary tables comparing manufacturing productivity and unit labour cost trends, go back to 1950 ; most, however, start sometime in the 1990s.

\section{OECD Labour Statistics}

<http://www.oecd.org/>

This section of the article is divided into two parts: for OECD iLibrary (formerly SourceOECD) subscribers and those who do not subscribe.

\section{Non-subscribers to OECD iLibrary}

Finding labour and employment statistics on the OECD site can be a little confusing, as there are three different pages that provide related information.

(1) From the above address, you can reach the OECD Statistics Portal

<http://www.oecd.org/statsportal/0,3352, en_2825_293564_1_1_1_1_1,00.html>

This has a section on Labour:

$<$ http://www.oecd.org/topicstatsportal/0,3398, en_2825_495670_1_1_1_1_1,00.html>

The Labour portion of their portal has two sections: "Labour statistics" (13 indicators) and "Unemployment Statistics" (6 indicators), along with links to various reports, definitions and other metadata. The links for each indicator can take one to a publicly accessible (i.e., to nonsubscribers) portion of OECD.Stat, or one of the OECD's many other labour- and employment-related databases. Much of the data are inaccessible to non-subscribers.

(2) The OECD also offers access to their content by general subject area; via this route, there is a section on "Employment"

<http://www.oecd.org/topic/0,3373, en_2649_37457_1_1_1_1_37457,00.html>

Clicking on 'Statistics" in the menu bar on this page leads one to a long list of discrete statistical publications on employment, many of which, but not all, are also under the "Unemployment statistics" heading on the OECD Statistics Portal page on Labour.

(3) The OECD also has a Directorate for Employment, Labour and Social Affairs

$<$ http://www.oecd.org/department/0,3355, en_2649_33729_1_1_1_1_1,00.html>

The link to "Statistics" within this section leads one to a page that is actually more helpful, in many ways, that the other two: a set of links to relevant pages of statistics are given at the top of the page. The relevant one is to Employment <http://www.oecd.org/els/employment/data $>$

- The Employment database offers current statistics for international comparisons and trends over time.

- Key Employment Statistics has summary tables for OECD countries with indicators on labour market outcomes and policies and how they compare with the OECD average.

In both cases, links to sources and relevant metadata are readily accessible.

While the written reports may be unique to the OECD, the data are derived from national labour force surveys. Given this, you may find it easier to use LABORSTA.

\section{Subscribers to OECD iLibrary $<$ http://www.oecd-ilibrary.org/>}

For subscribers, the quest is much simpler. From the OECD iLibrary home page, follow the link to "Statistics" at the top of the page, and then find "OECD Employment and Labour Market Statistics" in the list of available databases. The abstract states that this database

$$
\begin{aligned}
& \text { includes a range of annual labour market statistics } \\
& \text { and indicators from } 1960 \text { broken down by sex } \\
& \text { and age as well as information about part-time } \\
& \text { and short-time workers, job tenure, hours worked, } \\
& \text { unemployment duration, trade union, employment } \\
& \text { protection legislation, minimum wages, labour market } \\
& \text { programmes for OECD countries and non-member } \\
& \text { economies. }
\end{aligned}
$$

The data are more accessible, and many preconfigured tables are available. Related OECD publications are clearly 
indicated. A nice feature of the new iLibrary is a link, for each available dataset, to a page that provides a citation and links to download the citation information to a variety of citation managers

\section{Cite this content as:}

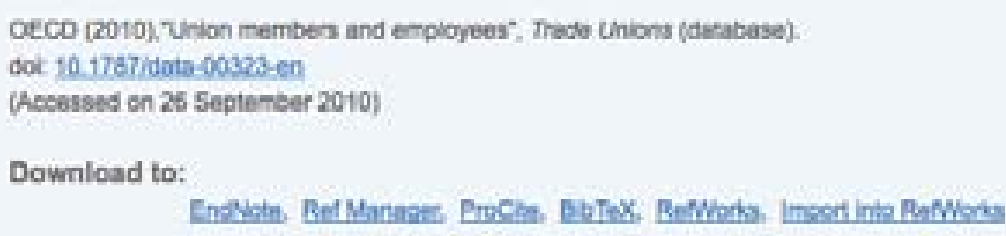

\section{OTHER RELATED SITES}

A source that can be generally useful in finding or interpreting labour data is How to find labour statistics ${ }^{11}$ The focus is naturally on the ILO's resources, but it does offer a selection of resources available to the public from other international organizations and partner institutions. Resources, including a variety of metadata, are listed by topic as well as either globally or regionally.

\section{PROBLEMS OF COMPARING DATA FROM DIF- FERENT COUNTRIES}

As alluded to earlier, problems can occur when attempting to compare data across geographies. In the ILO definitions of terminology, one frequently encounters phrases such as "National definitions of [desired criterion] may differ from the recommended international standard definition" or "National practices vary between countries" or "The comparability of the data is hampered by the differences between countries and even within a country". A concrete example: in Canada, a part-time worker is one who usually works less than 30 hours per week; in Australia and the U.S, the criterion is less than 35 hours or more per week, and in the EU, it is whatever the individual being asked considers part-time work. In addition, in terms of classifying one's status as employed vs. employer, most countries classify managers and directors of incorporated enterprises as employees, while in some others they are classified as employers. One wonders if comparability is possible at all.

Efforts are being made to create labour data that can be compared across national boundaries. As previously mentioned, the KILM database incorporates efforts to create harmonized variables that are comparable between countries. Other efforts include the CrossNational Equivalent File (CNEF project based at Cornell University ${ }^{12}$, which includes "equivalently defined variables" for data from the U.K., Australia, Korea, U.S., Switzerland, Canada and Germany. The Comparative Perspectives Database, an offshoot of the Gender \& Work Database ${ }^{13}$, is a project that is attempting to create a variety of cross-tabulations on the subject of precarious employment using data from the U.S., Canada, Australia and the countries of the European Union. These efforts, as well as others, will make the task of comparability much simpler, albeit not as comprehensively as one might like.

Making variables have equivalent definitions is not necessarily an ideal solution either. The legal and regulatory frameworks surrounding labour and employment are dependant on national definitions; creating equivalent definitions removes the data from its national context, thereby, in some ways, making the data less relevant to the people and environment it represents. It is an issue one has to keep in mind, depending on the reason for comparing the data.

The important thing to remember, when attempting to compare statistics on similar parameters from different countries, is to examine the metadata, especially the definitions, closely to make sure apples are being compared to apples, not apples to pineapples, as it were. Just because something is called the same thing does not mean it is the same thing. Ultimately, it is the responsibility of the user of the data/statistics to ensure that their use is appropriate, but the data professional can, at least, alert her/him to the issues.

\section{REFERENCES}

1 Author contact information: Walter W. Giesbrecht, 203E Scott Library, York University, Toronto, ON, Canada M3J 1P3 (email: walterg@yorku.ca)

2 "About the ILO", International Labour Organization, accessed August 18, 2010, http://www.ilo.org/global/ About_the_ILO/lang--en/index.htm.

3 "Statistics and databases - What we do", International Labour Organization, accessed August 18, 2010, http:// www.ilo.org/global/What_we_do/Statistics/lang--en/index. htm.

4 "Sources and Methods: Labour Statistics", International Labour Organization, accessed September 25, 2010, http:// laborsta.ilo.org/applv8/data/SSMe.html.

5 "Sources and Methods in Labour Statistics", International Labour Organization, accessed September 27, 2010, http://www.ilo.org/stat/Publications/sources/.

6 "Key Indicators of the Labour Market (KILM), Sixth Edition ",International Labour Organization, accessed September 26, 2010, http://www.ilo.org/empelm/what/ pubs/lang--en/WCMS_114060/index.htm 
7 "World Development Indicators “,World Bank, accessed September 26, 2010, http://data.worldbank.org/datacatalog/world-development-indicators.

8 "Guide to understanding the KILM", International Labour Organization, accessed September 26, 2010, http://kilm.ilo.org/KILMnetBeta/pdf/Guide\%20to\%20 understanding\%20the\%20KILMEN-2009.pdf.

9 "ILO Global Job Crisis Observatory", International Labour Organization, accessed September 26, 2010, http:// www.ilo.org/pls/apex/f?p=109:1:0.

10 "International Comparisons of Annual Labor Force Statistics, Adjusted to U.S. Concepts, 10 Countries, 19702009: Introduction", Bureau of Labor Statistics, accessed September 26, 2010, http://www.bls.gov/fls/flscomparelf/ notes.htm\#introduction.

11 "How to find labour statistics “,International Labour Organization, accessed September 26, 2010, http://www.ilo. org/public/english/support/lib/resource/subject/labourstat. htm.

12 "Cornell University User Package for the CrossNational Equivalent File (CNEF), 1970-2008 “, Department of Policy Analysis and Management, Cornell University, accessed September 27, 2010, http://www. human.cornell.edu/pam/research/centers-programs/germanpanel/cnef.cfm.

13 "gender \& work database", accessed September 27, 2010, http://www.genderwork.ca. 